\title{
Dynamic Asset Allocation by Applying Regime Detection Analysis
}

\author{
Woo Chang Kim ${ }^{\dagger}$ \\ Industrial and Systems Engineering Department, KAIST \\ Regime 탐지 분석을 이용한 동적 자산 배분 기법 \\ 김 우창 \\ KAIST 산업및시스템공학과

\begin{abstract}
In this paper, I propose a new asset allocation framework to cope with the dynamic nature of the financial market. The investment performance can be much improved by protecting the capital from the market crashes, and such crashes can be pre-identified with high probabilities by regime detection analysis via a specialized unsupervised machine learning technique.
\end{abstract}

Keywords: Asset Allocation, Regime Detection, Machine Learning

\section{Introduction}

An old template for the asset allocation going back to Merton (1969) is the famous fixed mix of the traditional asset classes such as the static 60 40 stock-bond mix. For the last several decades, this approach proves to be quite robust, and has provided reasonable performance to the investors. However, as we are now living in a world where the global financial market behaves nothing like what we've seen for the last 50 years, it is reasonable for us to re-assess the possibility of success of this traditional approach in the post-crisis market. In this study, I show that the existing static approach could lead to a significant downside risk, and propose an alternative asset allocation framework based on regime detection approach which could improve the investment performance during the crash periods.

\section{Why Dynamic Asset Allocation?}

What are the main problems of the static asset allocations? In order to address this, we first need to identify the "implicit" assumptions for this traditional approach as stated below, and then check if those assumptions have been, or will be held in the future as well:

- Both stocks and bonds will have positive returns in the long run

- Stocks will outperform the bonds in the long run

Unfortunately, it seems that the assumptions above have failed to hold for the last several decades, not to speak of the future - as illustrated in $<$ Figure $1>$ and $<$ Figure $2>$, both bonds and stocks have had large drawdowns over decades in real terms, and more importantly, bonds have outperformed equities over several decades.

This implies that it is very possible that the equity market is flat or even negative for more than several years along with significant drawdown periods. From this, one can easily conclude that the traditional fixed mix approach or more specifically, the static asset allocation is not necessarily the best approach for the long-term investors. It is obvious that the dynamic approach is a must for the success. See Mulvey et al. (2003) for the detailed discussions on this topic.

This study was supported by National Research Foundation of Korea (grant number : N01120369).

† Corresponding author : Woo Chang Kim, Industrial and Systems Engineering Department, KAIST, 373-3 Guseong-dong, Yuseong-gu, Daejeon, 305-701, Korea, Tel : +82-42-350-3102, Fax :+82-42-350-3110, E-mail : wkim@kaist.ac.kr.

Received November 6, 2012; Accepted November 20, 2012. 


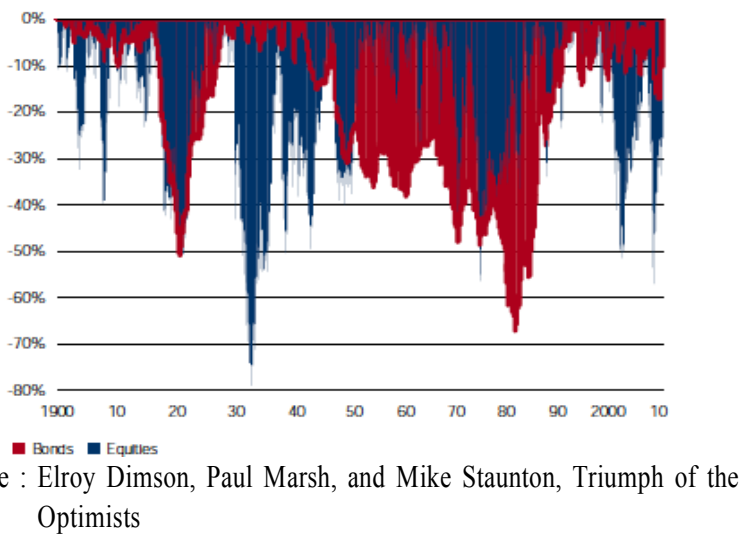

Figure 1. Drawdown on US equities has exceeded that of bonds for the last several decades

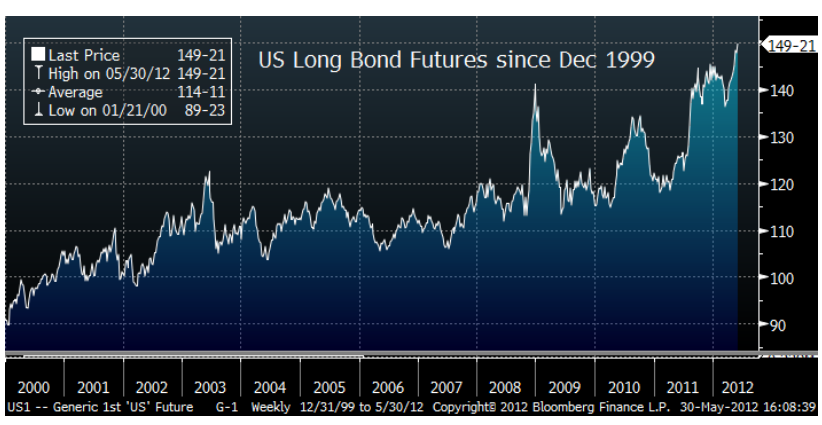

Figure 2. The bonds have steadily grown in value over the last decade

\section{Key Ingredient for Dynamic Asset Allocation: Regime Detection via Machine Learning Methods}

Then what is the key for the success of the dynamic approach? It is well known that the equity returns have occurred in long-term bull markets. Also, even during the bear market periods, the losses take place during the sharp drop that happens in a relatively short period. This clearly implies that the equity return distribution is negatively skewed. The effect of the negative skewness to the investment performance can be clearly illustrated by the following example as in $\langle$ Table $1>$.

From 1973 to 2011, the annualized return on the U.S. stock market index was $9.82 \%$ and the final wealth with an initial investment of $\$ 1$ was $\$ 38.61$. If the investor could avoid the return on the worst day at the cost of realizing the return on the best day among 10,174 daily returns, the annual return increases to $10.10 \%$, providing an additional 28 basis points compared to the investment performance without truncating the extreme events on both sides (i.e., the unconditional investment performance). As an extreme example, when 39 worst and best returns (once-a-year events) are excluded from the original data, the investor could enjoy over 100 basis points of incremental return relative to the unconditional return.

Clearly, an investment strategy with a focus on protecting against extreme downside outcomes would have better performance than pursuing extreme good returns. This provides a simple answer for the success of the dynamic portfolio management : avoid the sharp drawdown (or crash) period from the equity market even if it costs some upsides. Thus, our main task is to identify if the current market state or the regime is the crash or not.

In the engineering sciences, regime identification technologies have been extensively studied, and as a consequence, we all are utilizing such technologies in our daily lives. One of the good examples is the voice recognition tool that has become very common along with the wide utilization of the smart phones. While the details of this technology could be quite mathematical, the idea is fairly simple-let the "machine" recognize the voice patterns, and find the text that best matches the voice input. And as we all know, this approach works quite well.

The very same technology can be applied to the financial market in order to identify the market regimes. More specifically, I utilize the Hidden Markov Model (HMM) to 25 equity markets and find the followings, which are illustrated in <Figure 3>. See Gorton and Rouwenhorst (2006) and Prajogo (2011) for the detailed discussions on the applications of HMM to the financial markets.

- Finding 1 : All equity markets have three regimes-growth, sideways, and crash - and the returns of the equity markets are ordered as growth $>$ sideways $>$ crash. Herein, the sharp drawdown periods are mostly included in the crash regimes.

- Finding 2 : In all equity markets, the probability of today's regime being the same as that of yesterday is very high, typically exceeding $95 \%$.

- Finding 3 : If yesterday's regime was growth, the probability of today's regime being crash is practically 0 . Likewise, if yesterday's regime was crash, today's regime never becomes growth.

Table 1. Investment performance of the U.S. market from January 1, 1973 to December 31, 2011-In addition to the unconditional performance, annual returns and total wealth when the same numbers of extremely good and bad returns are excluded are reported

\begin{tabular}{lccc}
\hline & Annual Return & Difference & Total Wealth \\
\hline Datastream U.S. Market Index & $9.82 \%$ & & 38.61 \\
Exclude Returns on Worst and Best Days & $10.10 \%$ & $0.28 \%$ & 42.57 \\
Exclude Returns on 5 Worst and Best Days & $10.23 \%$ & $0.41 \%$ & 44.59 \\
Exclude Returns on 39 Worst and Best Days & $10.90 \%$ & $1.08 \%$ & 56.50 \\
\hline
\end{tabular}




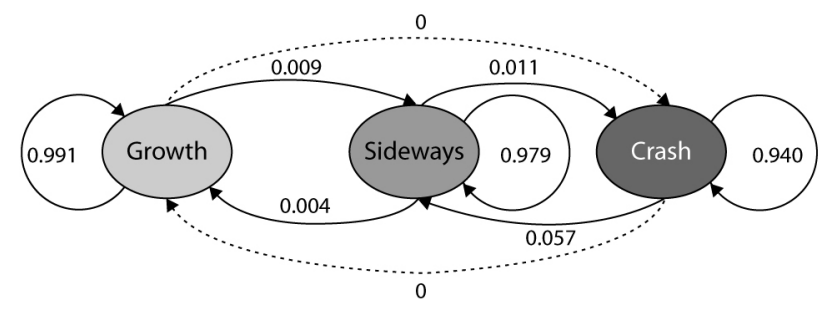

Figure 3. Graphical representation of typical equity market regimes-the number next to each arc represents the transition probability between two regimes

These findings provide the critical hint to the task of avoiding the market crashes. Firstly, finding 1 suggests that investors could enjoy the upside movement of equity markets under the growth and the sideways regimes, while it is reasonable to reduce the equity exposure during the crash regimes.

Secondly, finding 2 implies that the regime do not switch very frequently. This has a great implication for the actual investment decision making process as the number of regime switching is proportionate to the slippage costs.

Lastly, and most importantly, finding 3 allows us to have the sideways regime as the "warning sign" for the crash regime being ahead. If the today's regime is growth, the chance of experiencing

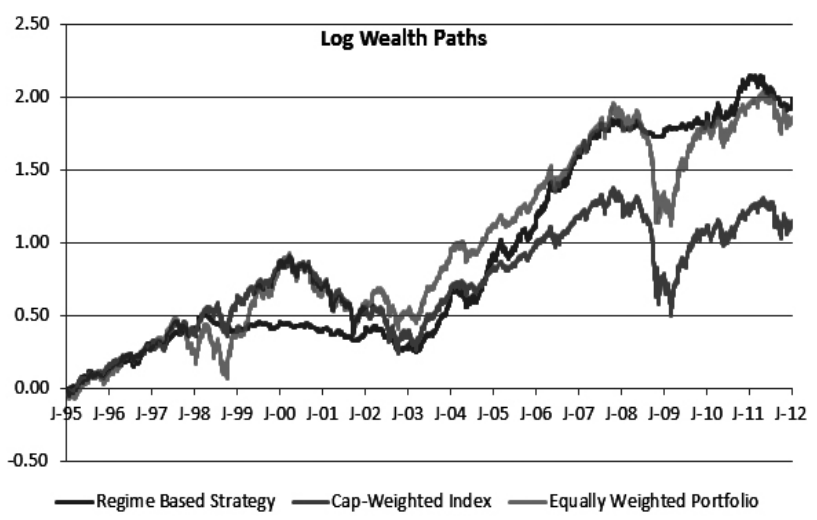

\begin{tabular}{c|c|c|c}
\hline \multicolumn{4}{c}{ January 1,1995 to December 26, 2011 } \\
\hline & $\begin{array}{c}\text { Regime Based } \\
\text { Strategy }\end{array}$ & $\begin{array}{c}\text { Cap-Weighted } \\
\text { Index }\end{array}$ & $\begin{array}{c}\text { Equally } \\
\text { Weighted Index }\end{array}$ \\
\hline Return & $12.41 \%$ & $7.00 \%$ & $11.57 \%$ \\
\hline Volatility & $9.23 \%$ & $15.44 \%$ & $15.73 \%$ \\
\hline Sharpe Ratio & 1.02 & 0.26 & 0.54 \\
\hline $\begin{array}{c}\text { Max } \\
\text { Drawdown }\end{array}$ & $23.81 \%$ & $58.36 \%$ & $56.76 \%$ \\
\hline $\begin{array}{c}\text { Return/ } \\
\text { Drawdown }\end{array}$ & 0.52 & 0.12 & 0.20 \\
\hline Ulcer Index & $8.74 \%$ & $20.67 \%$ & $18.04 \%$ \\
\hline UPI & 1.08 & 0.19 & 0.48 \\
\hline
\end{tabular}

Figure 4. Performance of regime based strategy compared to typical market benchmarks the crash tomorrow is almost negligible, letting us engage the equity exposure quite aggressively without much risk of the sharp drawdown. If today's regime is sideways, there is a good chance of sharp drop in the near future, thus one should revise the portfolio to be less aggressive. Needless to say, it is best to reduce or eliminate the equity exposure during the crash regime.

$<$ Figure $4>$ depicts the performance of the equity only investment strategy that utilizes the findings above. More specifically, the regime based strategy invests in the 26 regional market index ETFs, where each country ETF is turned on with a relative weight of $1 / 26$ under the growth regime, while is turned off during other regimes. The test has been conducted in a purely out-of-sample manner, and more notably, the strategy didn't suffer from the sharp market crash in 2008, which resulted in the superior investment performance.

In fact, the equity universe is not the only asset class that the regime identification technology can be utilized. <Figure 5> illustrates the results of the regime identification analysis on the commodity index using the DJ-UBS commodity index. As in the equity market case, the regime identification system can detect the sharp drop in the commodity market that took place in 2008 along with the equity market crash, which could have helped the investors if properly utilized. See Bae (2012) for the detailed discussions on the HMM based regime identification in the commodity markets.

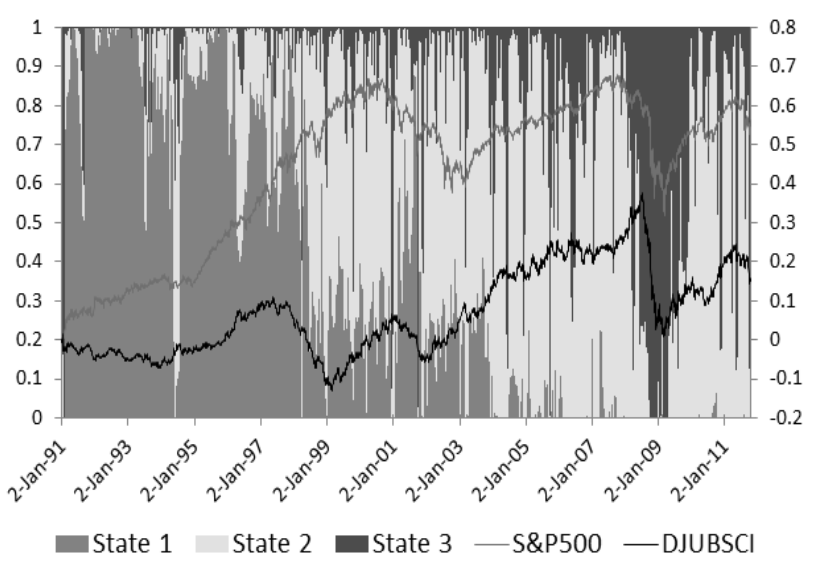

Figure 5. Regimes of broad commodity index from 1991 to 2011

\section{Conclusions and Discussions}

In this study, I have illustrated that the static asset allocation could result in adverse investment outcome when a sharp market drop occurs. As an alternative, I propose a dynamic asset allocation approach based on the regime detection models. The regime identification procedure based on the Hidden Markov Model could be a good starting point as it shows good performance in both equity and commodity markets. I advocate that, by combining the regime detection analysis with the traditional optimization based asset allocation, one could possibly achieve stable capital growth. 


\section{References}

Bae, G. I. (2012), What are the Regimes in the Commodity Market?, Master's Thesis, KAIST.

Gorton, G. and Rouwenhorst, K. G. (2006), Facts and Fantasies about Commodity Futures, Financial Analysts Journal, 62, 47-68.

Merton, R. C. (1969), Lifetime Portfolio Selection under Uncertainty : the Continuous-Time Case, Rev. Economics Statistics, 51, 247 257.

Mulvey, J. M., Pauling, B., and Madey, R. E. (2003), Advantages of Multiperiod Portfolio Models, Journal of Portfolio Management, 29, 35-45.

Prajogo, A. (2011), Analyzing Patterns in the Equity Market : ETF Investor Sentiment and Corporate Cash Holding, Ph.D. Thesis, Princeton University. 